\title{
MAXIMIZING ENTREPRENEURSHIP LEARNING/TRAINING BENEFITS
}

M-Said OUKIL ${ }^{\star}$

Received date: $* * / * * / 2017$, Accepted date: $* * / * * / 2017$, Online publication date: $* * / * * / 2017$

\begin{abstract}
As an educator who strives for highest quality university teaching, I do my best to create a complete immersion of my students in learning from theory, best practices, real examples and a great variety of in- and out- of university and class activities. Hence, my approach in teaching entrepreneurship courses in particular, consists of providing with every possible tip to make learning cognitive, fun, closest to reality and effectively productive and promising. Believing in the fundamental link or relationship, between innovation and entrepreneurship, I do focus very much on stimulating creativity through individual and team-based assignments, as well as games and picture-based exercises. Problem-solving games and exercises are particularly used. A best expected outcome in my entrepreneurship courses is a choice for enrolled students to create either a spin-off company, or a sound business plan to implement after graduation, individually or collectively. A major policy implication is the need for great improvements in courses content and teaching methods.
\end{abstract}

Keyword: Entrepreneurship, quality education, Algeria

JEL Code: L26, M13, M53, D83, P36.

Citation: OUKIL, M. S. (2017). Maximizing Entrepreneurship learning/training benefits. Journal of Finance and Corporate Governance, Vol., 1, No. 1: pp. 07 - 15. (Jun 2017); ISSN: 2602-5655.

\section{INTRODUCTION}

Perspectives are very much promising as higher education students all over the world and in Algeria become interested in self-employment and in contributing to economic growth and development of their societies. Evidence indicates that with very few exceptions, students get very much excited and express their intention to go business either immediately after

\footnotetext{
$\star$ Prof. of Innovation and Entrepreneurship, University of Algiers-3, Algiers, prof.oukil@ gmail.com
} 
graduation, or sometime later with more practical experience. While in the short term, many seek degrees for immediate recruitment purposes, but in the medium and long term, they aspire at creating their own businesses with a greatest impact possible on the economy and society. However, given the general fear surrounding any business adventure, it is becomes very much crucial to enlighten students about the different aspects surrounding the issue.

This paper describes a modest experience showing how to prepare graduates to become knowledgeable, skilled and confident entrepreneurs, thus ready to face the challenges in the real world that is full of constraints and obstacles. In Algeria, fortunately since last year, the course of entrepreneurship has been institutionalized in universities and became a core course in various disciplines. Besides that, "Diar al Muqawalatiya" or entrepreneurship houses have also been formally created in almost all university campuses in order to boost entrepreneurial actions. This, therefore, puts a great challenge on professors and trainers to upgrade the teaching quality in order to maximize the learning outcomes of the students, such that they can develop the skills and capabilities and knowledge to launch new businesses and start-ups successfully. A major point here is that, those instructors who refuse or do not like to improve their way of teaching are not practically recognizing the changes imposed by the new knowledge, technologies and conditions.

\section{LITERATURE REVIEW}

According to Duke (1996), introductory courses in entrepreneurship or new venture creation, offered by US universities, score a highest frequency (48\%) among other business and management courses. Such a high percentage shows the attraction of entrepreneurship courses to students and graduates in the United States.

In this present paper, the author describes his teaching experience of two entrepreneurship courses. In a related paper, he explored an interesting case of students at King Fahd University of Petroleum and Minerals (Kfupm) as a leading university in Saudi Arabia (Oukil, 2008). The case clearly shows that when ne way of explaining and new tips are introduced, students pay more attention and their learning interest increases.

The instructor's quite long involvement in teaching business and management courses made him believe that, as there is no one best way in management to stick to, there is much room for improvements and advances in all fields and activities. Even though the debate, whether teaching entrepreneurship can be taught or not, is not definitely settled, but there are many strong arguments in favor (Hynes, 1996; Henderson and Robertson, 2000; Kuip and Verheul, 2003; Jones and English, 2004; Henry \& al, 2005; Man, 2007). The consensus among all these few selected authors and that of the present author allows saying that in order to maximize the benefits and outcomes to students a comprehensively new way of teaching/learning entrepreneurship is desirable and possible. Nevertheless, as conditions continuously change, challenges are always there to find new innovative approaches to teaching entrepreneurship and make it a benefic experience to students (Colin, 2013).

Truly, as learning entrepreneurship is not only about being aware of principles and understanding theories; what it does require more are passion, skills, confidence and beyond that practice (Neck et al, 2014). Further, for students, having an idea about launching a business could well be speeded through all sorts of learning when they are motivated (Fayolle et al, 2014). All this suggest that combining theory and practice should therefore be fruitful and make the concerned students interested to learn deeply and reach application stages of the knowledge they acquire.

Accordingly, components of the entrepreneurship course the present author has been delivering for many years range from use of power point presentations, to handouts, case 
studies with local and international flavor, individual exercises, online tests, videos, collective exercises and games, and to extracurricular activities and exploring the real business world. The instructor does even ask his students to engage in small physical movements during some in- and out- class exercises and games. Ultimately, and apart from formal office hours, informal interactions and connectivity are very much encouraged by the professor.

The author's proposed model of teaching the course of entrepreneurship, here, is steamed from his passion and quite long experience at both graduate and post-graduate levels in Algeria and abroad. His work experience spans from teaching various management courses, including feasibility project analysis, family business, small businesses, business intelligence and innovation management for more than three decades.

The initiative of making the course benefic and the same time joyful also steams from the author's sincere desire to expose students attending his classes to the world of business, in general, and entrepreneurship, in particular. Through a campaign aiming at a greatest possible awareness, the undertaken task consists of engaging and enhancing students to think business and entrepreneurship. Those who attend the course are, thus, guided to understand the real importance of self-employment and innovation, therefore going beyond just launching any kind of business to benefit the economy and society, and why not customers in the whole world. Ultimately, the hope is for students to take a concrete action to create their own business firms, either while they are at the university, or alternatively sometimes after graduation.

The author's teaching method is substantially of an interactive, persuasive and full immersion nature. The belief is that this is crucial because students may not always be able to maximize learning on their own. On the other hand, contemporary students are generally more inclined to inclusive learning and practical outcomes, i.e., studying within an enhancing environment and learn what do to with the knowledge they acquire.

Accordingly, the author's role has always been to encourage and facilitate the transformation of theories, principles and ideas into meanings and concrete outcomes. As engineering and technology students are supposed to design new or improved products or systems, taking management course could indeed help them, just like economics, commerce, finance, marketing, management and business students, to ultimately create and launch their own businesses or start-ups. The author's specific view is that entrepreneurship cannot be limited to one discipline. To say that all students should have an opportunity to learn about the subject, regardless whether they want or not to engage in business.

\section{METHODOLOGY}

Stepping forward to act, or lunching a business may have to be often ignited, particularly in the case of students or young people who fear the unknown and failure. This is the basic reason why enhancing awareness as well as learning is important and fruitful, namely for those who have ideas, but hesitate to take real or immediate action. In this context, the specific objectives of our approach are:

1. Full and systemic perception of business and entrepreneurship through:

a. Good understanding of business undertakings, opportunities and value creation;

b. Realizing the very need to consider the various aspects surrounding business (financial, economic, social, legal, ethical, cultural and environmental);

c. Comprehending the impacts of business for owners themselves and the collectivity;

2. Identifying triggers and barriers to entrepreneurship and how to react;

3. Understanding the important role of social entrepreneurs and corporate entrepreneurship;

4. Analyzing real-world issues and inspiring from them pragmatism and practice; 
5. Demonstrating the capability of developing effective and sound business plans and businesses models;

6. Being able to explain the difference between risk and uncertainty and what is takes to be an entrepreneur;

7. Recognizing the importance of self-employment including hands-on work;

8. Perceiving the global role of entrepreneurs;

9. Identifying best practices of managing human resources and the advantage of teamwork in modern business in both private and public organizations;

10. Understanding the crucial role of technological and organizational innovations in performance, competitiveness and growth.

\section{THE INITIATIVE AND INVOLVED ACTIVITIES}

The presented initiative of teaching entrepreneurship in a different way has started about many years ago at the graduate level with the offering of the Entrepreneurship and Small Business Management (MGT-527) for the first time at Kfupm, in Dhahran, Saudi Arabia. At the beginning of semester 1, in 2014, the College of Industrial Management (CIM) started offering a same named but differently encoded course (MGT-412), in replacement of the old course of feasibility project analysis (MGT-448) for undergraduate students. Hence, all of these two courses students at both graduate and undergraduate levels have been all concerned by the new learning process.

However, the degree of complexity of provided material and extent of activities and interactivity do vary from one level to the other. Textbooks, for instance, are different and home works at the end of each chapter are optional, but highly recommended for undergraduate students. With two classes of one hour and a quarter per week, sessions are arranged and scheduled in a way to cover the relevant textbook chapters' main points, and allow between twenty to thirty minutes for additional pedagogical work or activities. These include critical, reflective and analytical thinking, communication and multi-cultural exercises, problem solving, tests, home works and games, either individually or team-based.

In what follows the author presents entrepreneurship course components with some specific examples of such used activities:

$>$ Exercises:

1. Business ownership;

2. E-commerce;

3. Pricing;

4. Decision-making and choice of alternatives;

5. Ideation or idea generation.

\section{Tests:}

1. Evaluation of entrepreneurial potential $\left(1^{\text {st }}\right.$ or $2^{\text {nd }}$ session with comments and discussion);

2. Re-evaluation of entrepreneurial potential (half way through the semester);

3. Scenarios;

4. Personal characteristics

5. Final evaluation of entrepreneurial potential (end of semester).

Home works:

1. Preparing case studies (local) and/or (international);

2. Experiential exercises (end of chapters of the adopted textbook);

3. Study of national patent system and intellectual property;

4. Choice of three best books on entrepreneurship; 
5. Which is your favourite quote about entrepreneurship?

$>$ Games:

1. Creating an entrepreneurship mind set;

2. Joining the stars by four straight lines;

3. Communicating;

4. Find your passion;

5. Screen off an item of your choice.

Guest speaker:

1. Experienced local entrepreneur;

2. Experienced foreign innovator;

3. Experienced instructor or researcher interested in innovation and entrepreneurship.

\section{Field work:}

1. Interviewing a local entrepreneur (man or woman);

2. Reporting about a visit to an incubator / accelerator;

3. Asking students about family businesses.

Videos:

1. Funding choices;

2. Making meaning;

3. What to do with little money;

4. Importance of teamwork.

Team-based exercises/games:

1. Communication;

2. Leadership;

3. Testing ideas.

\section{TEAM FORMATION AND TOOLS}

As already mentioned, and according to Hashimoto (2012), entrepreneurial teams create most of new start-ups. To reflect this reality, the present author/instructor very much emphasises the role of teams and collectively prepared projects, because they could be more effective than case studies (McMullan and Boberg, 1991). At the undergraduate level, the instructor himself forms teams, after the university registrar uploads the final list of enrolled students. The purpose is to have a best mix possible of majors, thus giving the chance for complementarities of various disciplines and competencies. In the Kfupm case and its College of Industrial Management with its three departments, teams include students, whenever possible from management and marketing department, economics and finance, and accounting and management of information systems. Of course, the ideal would be team members from different departments, male and female, national and foreign students.

A rule that has been set by the instructor is that students, having previously formed teams in other courses, cannot do the same, particularly when members are from one discipline or major. Even though the outcome of the concerned team could possibly be positive, but the systemic perspective is emphasised. For, comprehensive learning of entrepreneurship cannot be limited to one or a few particular disciplines. Only at the graduate level, that the instructor therefore gives freedom to students to form their own teams, due to mainly their higher level of maturity and diversified work experience.

Smart classes are, of course, very much useful to conduct the course in question. Power point presentations, provided by the publisher, are used as the basic material in the teaching process. However, the instructor does introduce small changes to the slides by adding, for instance, updated data or relevant data, website links, attractive pictures or photos 
and local favour, etc. Circular smart classrooms are generally preferred by students and they are very much useful particularly in the absence of circular tables.

Internet services that work appropriately throughout departments are also useful. This does indeed help students to, for instance, take and retake online tests, have access to e-books and papers, and watch the selected videos. However, at the very beginning of each semester, the instructor prefers to conduct a paper-based entrepreneurship test. The advantage consists in providing feedback, followed by a discussion about the scores and their meaning, (scores are divided into three categories: $\mathrm{a}, \mathrm{b}$, and $\mathrm{c}$, referring to dispositions of students to go business, either immediately on their own, or with support from someone, or to consider the option after much more learning. The instructor always draws the attention of his students to the perspectives of change in scores, with emphasis on the possibility of improving them at the end of semester, or even in the future after graduation, or even later on.

\section{CURRENT AND FUTURE CHALENGES}

The basic challenge for the instructor was to make a successful shift from the formal traditional way of teaching namely as restricted to one textbook, repeated old home works, same quizzes, midterms, final exams and end-of-semester text-based project or feasibility study, which students were used to. Consequently, and in order to attract students' attention and make them expressing their interest, love and enjoy the course, a change of learning method was necessary. Word of mouth, from previous students who took the course, helped very much the spread of the benefit of the new way of learning and training, as well as the possibility of creating a potential business and pursuing personal dreams. However, while the course is a core course at the undergraduate level, at the MBA level it is still an elective one. This could, unfortunately, limit the development of entrepreneurship education as wide as possible in any institution. Hope is that in Algeria, the entrepreneurship course should be a core course also at the doctorate level as it is so at present at the master level.

Another challenge, perhaps rendering the course a little bit less benefit than it should be, is the problem of diversity. At Kfupm, all students are male, all or the greatest majority are Saudis, and most of them speak a maximum of two languages only, i.e., English and Arabic. All of that and the monoculture, in particular, may have made the learning process less optimal or limited in its learning outcomes.

In a diversified context or situation, learning is personal as well as collective, and from different cultures and horizons, and this has been missing in my classes at Kfupm. Now, the case in Algeria is different. In particular, female students in Algeria are witnessed to be striving for excellence, and could therefore be a key factor in developing the entrepreneurship spirit and upgrade the aspiration of Algerian youth. Besides all that, there are also some foreign students with different cultures and speaking languages.

Apart from that, and since quite a long time, the author expressed his wish to the Kfupm Administration, through his department, to have better class arrangements easing teamwork and freer movement of students in the classroom. The benefit of this is avoiding time waste in teamwork settings, during the scheduled sessions. The implementation that has just started across the university does not solve the problem definitely, since request for smart classes is higher among the different colleges and department. Beyond that, the open enrollment of students reaching sometimes 40 individuals per section could leave the learning process effectively limited. Practical experience may not also be possible in situations with no provision of even small tangible assets and pedagogical tools. Unfortunately, these are also major obstacles at present in the case of Algeria. 
Vol. 1, No. 1 (Jun 2017); ISSN: 2602-5655

\section{STUDENTS' FEEDBACK}

All students who have attended the course enthusiastically loved and enjoyed the new teaching and learning method. Through observation and examination of attendance sheets, the rate of absenteeism and latecomers has dropped sensibly, as students were motivated not to miss any part of the course or even the sessions. Passion as a requirement to become a successful entrepreneurs seems making students very keen to attend the sessions and enhanced them to devote full attention to learn how to start-up a business with concrete implementation on the ground. Given the differences in students' majors (Management and Marketing; Finance and Economics; Accounting and Management of information Systems), the idea of starting a business at the earliest time possible was very appealing to the greatest majority of the attendants.

As it is not possible to expect all people to become entrepreneurs, only very few students did not actually show much interest to start their businesses, since they prefer non business careers, such as teaching, management in organizations, finance, marketing, accounting and information expertise. The approach, used to maximize benefits, was to bring real and concrete examples of successful people (business man/women; innovators and entrepreneurs), products, processes, cases, situations and from different sectors and countries. And, this is what all students love: to feel, see and appreciate outcomes from courses and programs. One important thing to note is that the instructor and the students share active search for case studies of male and female entrepreneurs from particularly Muslim and Arab countries to reflect local conditions and culture.

For those students who had already embarked on their own business (before university enrollment or just after), the desire to learn more has been very clear, and directly and personally expressed to the instructor. Often, questions and discussion have indeed referred to real situations, problems and difficulties they encounter in their Saudi context. Such questions and discussions allowed more or deeper understanding of both theoretical and practical issues, and helped students seeing things clearer, which is important to avoid confusion and reduce mistakes or errors of various kinds, particularly when engaging real resources or savings.

Asking about the existence of various facilities available in Kfupm, their role and their activities, often reveals the extremely low rate of students who know about facilities, such as the incubator or fablab, and the many benefits they can provide to them. Only, very few students state that they are aware about such facilities, even if they did never approach them. The same is with regard to business competitions, both national and international, and the same for events relevant to entrepreneurship. Such awareness is of course very important as it could make students decide to participate or pursue their studies, or promptly engage in entrepreneurship, locally or internationally. Awareness is so much crucial in that it opens students' eyes on what is available and possible and offers chances to choose their careers and destinies.

\section{LEARNING OUTCOMES}

A very often noted fact is that, students get highly excited as they become able to more cognitively understand, and absorb the provided theoretical knowledge, expertise and relevant aspects of launching a business. All the class votes best end of term team-based projects after presentations, then recommended to the corresponding and appropriate structure within the University (incubator; innovation center and entrepreneurship institute). Alternatively, students themselves are encouraged to contact one of the mentioned centers or other parties in order to discuss the possibility of financing their individual projects to become real businesses. 
As just mentioned, taking this course makes students aware of local, regional and international business plan competitions. This is important because it gives chances of not only obtaining recognition, winning top positions and memorable rewards, but also to access to outside legal funding, particularly when students are passionate to start their own business on their own. Criteria set for best projects stipulated at the very beginning of the semester in the syllabus, or during the first session, are as follow:

$>$ Innovativeness and this consists of:

○ Original ideas (both patentable and non-patentable),

- New or improved products, processes, methods, services and systems, etc.,

- Advanced technology-based product or process innovations.

Socio-economic and environmental impacts:

o Job creation,

- Use of local inputs or as generally called as integration,

- Improving socio-economic conditions,

- Preservation of the environment and nature,

- Improving quality of life and wellbeing of people and generations.

Opportunity identification;

$\circ$ Finding a gap in commercializing a product or provided a service,

- Find a problem to solve,

$\circ$ Bringing something new or innovative.

Collective efforts from team members.

○ Peer evaluation is carried out,

- Team reflexivity through oral presentations,

- Team preparedness towards action to create the relevant business,

- Team engagement towards social responsibility,

$\circ$ Brainstorming is required among all members.

\section{CONCLUSIONS}

Aiming at benefiting all the attending students, the devoted entrepreneurship course's instructor and author of this paper exposed a new or different way of achieving that, without claiming any exclusive superiority. Intentionally, he keeps striving to serve his students in a way to fully immerse them in the world of entrepreneurship and innovation. He uses all possible tips, tools and means, including textbook and extra readings, videos, pictures, exercises, games, individual and teamwork, as well as extra-curricular activities and guest speakers. Also, and in order to learn from practice and real-world situations, the instructor gives the assignment of interviewing a local businessman/woman or entrepreneur a mark equivalent to the individual work. The use of technology, such as blackboard version 9.1, is found very useful in allowing non-stop and both formal and informal learning. Hope is for the same in Algeria in terms of use of technology and attractive way of in teaching, learning or training.

With modesty, the approach in question proves to be fruitful, fun and attracting to more and more students and participants. The ultimate objective is to provide quality entrepreneurship education and, consequently, bring the learning/training process to its maximum if not optimum. As a recommendation, quality entrepreneurship education across all university departments should spread more quickly as the condition of Algeria's economy and society evolve.

Overall, and given the increasing role of the private sector and family businesses in dealing with the crisis imposed by the fall of oil prices and the need to diversify economies, 
Vol. 1, No. 1 (Jun 2017); ISSN: 2602-5655

best teaching/learning/training practices become very much crucial to enhance job creation, economic growth, social and technological development, and must therefore be given particular attention in any reform and in all curricula revision across all levels of education and all over the country. At certain times, benchmarking and evaluation of progress could be useful to maximize or optimize learning and training of our students and youth. Entrepreneurship culture should make its way in Algerian universities and society at large.

\section{REFERENCES}

Colin, J. (2013). Teaching Entrepreneurship to Postgraduates, Edward Elgar Publishing limited, UK,

Duke, Ch. R. (1996). "Exploring Student Interest in Entrepreneurship Courses", Journal of Marketing Education, vol. 18, no. 3, pp. 35-45.

Fayolle, A. Linan, F., and Moriano, J.A. (2014). "Beyond entrepreneurial intentions: Values and motivations in entrepreneurship", International Entrepreneurship Management Journal, vol. 10, pp. 679-689.

Hashimoto, T. (2012). "A Literature Review of Entrepreneurial Team", in: H. Tan (Ed.): Technology for Education and Learning, AISC 136, pp. 221-226.

Henderson, R., and Robertson, M. (2000). "Who wants to be an entrepreneur? Young adult attitudes to entrepreneurship as a career", Career Development International, no. 5/6, pp. 279-287.

Henry, C., Hill, F., and Leitch, C. (2005). "Entrepreneurship education and training: can entrepreneurship be taught? Part I", Education Training, vol. 47, no. 2, pp. 98-111, and Part II, vol. 47, no. 3, pp. 158-169.

Hynes, B. (1996). "Entrepreneurship education and training - introducing entrepreneurship into non-business disciplines", Journal of European Industrial Training, vol. 41, no. 8/9, pp. 398-401.

Jones, C. and English, J. (2004). "A contemporary approach to entrepreneurship education", Education + Training, vol. 46, no. 8/9, pp. 416-423.

Kuip, I. V. D., and Verheul, I. (2003). "Early Development of Entrepreneurial Qualities: the Role of Initial Education", Centre for Advanced Small Business Economics, University of Rotterdam.

Man, T. W. Y. (2007). "Understanding entrepreneurial learning: A Competency approach", International Journal of Entrepreneurship and Innovation, vol. 8, no. 3, pp. 189-198.

McMullan, C. A. and Boberg, A. L. (1991). "The Relative Effectiveness of Projects in Teaching Entrepreneurship", Small Business \& Entrepreneurship, vol. 9, no. 1, pp. 1424.

Neck, H. M., Greene, P.G., and Brush, C. G. (2014). Teaching Entrepreneurship: A PracticeBased Approach, Edward Elgar. United Kingdom.

Oukil, M-S. (2008). "Technology Entrepreneurship Perspectives: A Survey of Kfupm Graduates (2001-2006)", Proceedings of the Third European International Conference on Innovation and Entrepreneurship, Winchester, UK, September 13-16. 